\title{
Faktor-Faktor Yang Mempengaruhi Agresivitas Remaja
}

\author{
Putri Rahmaning Sekar \\ Magister Psikologi, Program Pascasarjana, Universitas Ahmad Dahlan \\ Email :putisekar@gmail.com
}

\begin{abstract}
Aggressiveness is the desire to hurt other individuals, by expressing negative feelings such as hostility to achieve the desired goal. The aggressiveness component consists of physical aggression, verbal aggression, anger, and hostility. The purpose of this study is to identify the factors that influence aggressiveness. Literature searches were carried out on the Researchgate, Scopus, Springer, and Google Schoolar electronic databases using the keywords "aggressive behavior and aggressiveness". The research strategy of this research is a kind of systematic literature review research using qualitative (meta-synthesis) methods. The approach used in this research is meta-ethnograph. Search results show that aggressiveness is influenced by internal and external factors. These internal factors include: frustration, thinking disorders and adolescent intelligence, as well as emotional / emotional disturbances in adolescents while external factors include family or peer factors, school factors and environmental factors.
\end{abstract}

Keywords: Aggressiveness, Frustration, Thinking Disorders, Emotional Disorders

\begin{abstract}
Abstrak
Agresivitas adalah keinginan untuk menyakiti individu lain, dengan cara mengekspresikan perasaan negatifnya seperti permusuhan untuk mencapai tujuan yang diinginkan. Komponen agresivitas terdiri dari agresi fisik, agresi verbal, kemarahan, dan permusuhan. Tujuan penelitian ini adalah untuk mengidentifikasi faktor-faktor yang mempengaruhi agresivitas. Penelusuran literatur dilakukan pada database elektronik Researchgate, Scopus, Springer, dan Google Schoolar dengan menggunakan kata kunci "perilaku agresif dan agresivitas". Strategi penelusuran penelitian ini termasuk jenis penelitian systematic literature review dengan menggunakan metode kualitatif (meta-sintesis). Pendekatan yang digunakan dalam penelitian ini ialah meta-etnograf. Hasil penelusuran menunjukkan bahwa agresivitas dipengaruhi oleh faktor internal dan eksternal. Faktor internal tersebut meliputi: frustasi, gangguan berfikir dan intelegency remaja, serta gangguan perasaan/emosional pada remaja sedangkan faktor eksternal meliputi faktor keluarga atau teman sebaya, faktor sekolah dan faktor lingkungan.
\end{abstract}

Kata Kunci: Agresivitas, Frustasi, Gangguan berfikir, Gangguan emosional

\section{Pendahuluan}

Remaja merupakan masa terjadinya transisi dari anak-anak menuju masa dewasa, pada masa remaja terjadi proses pencarian jati diri yang dilakukan dengan berbagai upaya aktualisasi diri agar di akui oleh teman sebayanya. Proses pencarian jati diri banyak menimbulkan konflik baik bagi diri maupun orang lain. Menurut Hurlock[1] bahwa masa remaja merupakan masa yang sangat rentan terjadinya konflik karena banyak terjadi perubahan baik secara fisik amupun psikisnya. Perubahan fisik seperti pertumbuhan tinggi dan berat badan, kematangan fungsi reproduksi dan organ seksusal. Sedangkan pada psikis remaja merasa mampu memenuhi tanggung jawab seperti orang dewasa. Namun keadaan fisik dan psikis remaja masih belum memiliki kematangan layaknya orang dewasa. Namun banyaknya tuntutan sosial yang menyebabkan kegagalan sehingga hal tersebut menimbulkan frustasi dan konflik tersendiri bagi remaja. Masa remaja dapat dikatakan sebagai masa storm and stress, yang diwarnai dengan disequilibrium atau ketidakseimbangan sikap dan emosi, sehingga membuat remaja mudah berubah, bergejolak, dan tidak menentu Masa remaja juga merupakan masa transisi dimana pada masa itu diperlukan penyesuaian diri dari masa anak-anak ke masa dewasa. Pada masa tersebut kemungkinan akan, timbul masa kritis dengan ditandai kecenderungan munculnya perilaku menyimpang. Dalam kondisi tertentu, perilaku menyimpang Diterima Redaksi: 22-11-2020 | Selesai Revisi: 23-1-2021 | Diterbitkan Online: 24-1-2021 
akan berlangsung lebih lama dan akan menjadi perilaku mengganggu misalnya menyerang, merusak dan beberapa bentuk agresivitas lainnya [2]

Agresivitas adalah keinginan untuk menyakiti individu lain, dengan cara mengekspresikan perasaan negatifnya seperti permusuhan untuk mencapai tujuan yang diinginkan [3]. Mundy [4] menyebutkan bahwa kemunculan perilaku agresivitas dapat disebabkan karena berhadapan dengan situasi-situasi atau keadaan yang tidak menyenangkan dalam lingkungannya. Agresivitas sering kali disebabkan oleh amarah, yang merupakan jembatan psikologis antara komponen perilaku dan komponen kognitif dalam agresivitas. Individu pada umumnya menjadi lebih agresif ketika sedang marah dibandingkan saat tidak marah [3] Contoh dari perilaku agresif remaja yang terlihat jelas adalah semakin banyaknya berita yang disajikan setiap hari di media masa baik cetak maupun elektronik tentang perilaku kekerasan remaja baik secara individual maupun secara berkelompok, seperti tawuran, penganiayaan, penyiksaan, bahkan sampai menghilangkan nyawa [5]

Cornell, Peterson, \& Richards (1999) menyatakan bahwa amarah merupakan faktor predisposisi dari perilaku agresif dan amarah itu paralel dengan dorongan agresi[6], sehingga intervensi terhadap amarah perlu dilakukan sebagai sarana mengurangi perilaku agresif seseorang. Tingkat amarah yang tinggi di kalangan remaja awal sering terwujud dalam perilaku kejahatan, antisosial, kekerasan [7], prestasi belajar rendah, dan lemahnya kesehatan fisik dan mental hingga masa remaja akhir dan dewasa [8] .Penelitian [9] melaporkan bahwa subjek dengan tingkat amarah yang tinggi cenderung memiliki strategi koping yang destruktif; mengekspresikan amarah dengan cara menyerang orang dan benda secara fisik dan verbal; lebih banyak menantang dan berperilaku negatif; serta lebih sering mengalami konflik dengan orang lain. Berdasarkan fakta tersebut, maka remaja yang memiliki tingkat amarah yang tinggi dan berisiko berperilaku agresif, perlu mendapatkan perhatian dengan memberikan penanganan yang tepat dalam mengelola amarah dan mengendalikan dorongan agresinya. Berdasarkan pemaparan tersebut diatas, maka penelitian ini bertujuan untuk mengetahui faktor-faktor yang mempengaruhi agresivitas.

\section{Metode Penelitian}

Penelitian ini merupakan penelitian systematic literature review dengan menggunakan metode kualitatif dengan teknik meta sintesis. Pendekatan yang digunakan dalam penelitian ini adalah pendekatan metaetnograf, yaitu peneliti merangkum berbagai hasil penelitian yang relevan secara naratif agar dapat mengembangkan teori yang baru untuk melengkapi teori-teori sebelumnya. Penelusuran ini dilakukan pada tanggal 15 Mei melalui database elektronik seperti Researchgate (www.researchgate.net), Scopus (www.scopus.com), Springer (www.springer.com) dan Google Schoolar (scholar.google.co.id) dengan menggunakan kata kunci agresivitas. Database elektronik tersebut menyediakan berbagai hasil penelitian, salah satunya penelitian-penelitian di bidang psikologi. Kriteria seleksi berdasarkan hasil penelusuran yang telah dilakukan, peneliti menelaah dengan membaca judul dan abstrak untuk mengetahui apakah artikel yang dibaca sudah memenuhi kriteria untuk dikaji. Kriteria yang digunakan yaitu: 1) artikel penelitian membahas tentang agresivitas; 2) artikel membahas tentang pengaruh variabel $\mathrm{x}$ terhadap agresivitas; 3) artikel berisi laporan hasil penelitian; 4) artikel ditulis dalam Bahasa Indonesia dan Bahasa Inggris. Peneliti memperoleh 10 artikel publikasi setelah proses seleksi yang relevan untuk dikaji.

Analisis pada penelitian ini adalah peneliti melakukan identifikasi, evaluasi dan interpretasi terhadap semua hasil penelitian yang relevan terkait dengan agresivitas. Tujuan penelitian ini untuk mengindentifikasi faktor-faktor yang mempengaruhi agresivitas. Peneliti mengumpulkan beberapa artikel publikasi yang relevan untuk dikaji dan membuat rangkuman hasil penelitian yang terdiri dari nama peneliti, tahun publikasi, jumlah subjek, alat ukur yang digunakan serta hasil penelitian. Berdasarkan hasil tersebut peneliti membuat kesimpulan mengenai faktor-faktor yang mempengaruhi agresivitas. 


\section{Hasil Dan Pembahasan}

Berdasarkan hasil bacaan peneliti sebelumnya beberapa hasil penelitian yang relevan diperoleh sebagai berikut:

\section{Frustasi}

Faktor yang mempengaruhi agresivitas adalah frustrasi.[10] mendefinisikan frustasi adalah situasi dimana individu terhambat atau gagal dalam usaha mencapai tujuan tertentu yang diinginkanya, atau mengalami hambatan untuk bebas bertindak dalam rangka mencapai tujuan sedangkan frustrasi menurut [5]adalah terhambatnya atau tercegahnya upaya mencapai tujuan, dan kerap kali menjadi penyebab agresi. Orang yang frustrasi cenderung melakukan kekerasan ketika isyarat agresif menarik batasan dalam diri kemudian melepaskan kemarahan yang tertahan [11] Agresi merupakan salah satu cara merespon terhadap frustrasi. Frustasi ini bisa terjadi di sekolah, di rumah dan lingkungan sosialnya. Frustrasi terjadi bila seseorang terhalang oleh sesuatu hal dalam mencapai suatu tujuan, kebutuhan, keinginan, pengharapan atau tindakan tertentu. Frustasi karena tidak bisa mengikuti pelajaran di sekolah dengan baik, frustasi karena orangtua yang sering bertengkar dan kurang mendapat perhatian dari orangtua, frustasi karena tidak bisa memenuhi standar hidup seperti orang-orang lain di sekitarnya. Frustrasi dapat mengarahkan individu kepada bertindak agresif karena frustrasi itu bagi individu merupakan situasi yang tidak menyenangkan dan dia ingin mengatasi atau menghindarinya dengan berbagai cara, termasuk cara agresif. Menurut Berkowitz [10]Individu akan memilih tindakan agresif sebagai reaksi atau cara untuk mengatasi frustrasi yang dialaminya apabila terdapat stimulus-stimulus yang menunjangnya ke arah tindakan agresif itu .

\section{Gangguan Berfikir}

Faktor gangguan perfikir atau intelegensi Faktor gangguan berfikir merupakan pemikiran dan kepercayaan yang tidak baik dan dapat menyebabkan berbahasa kasar, menghina, bertengkar, mengejek dan marah-marah. Pemikiran tersebut dapat mendorong seseorang berbahasa kasar pada orang lain. Berdasarkan informasi yang diperoleh dari siswa melalui wawancara dikemukakan bahwa siswa yang berbicara kasar dan marah-marah dapat menolong dirinya karena ia dapat melawan ketika diganggu dan tidak merasa ada masalah, sehingga ia cenderung berbahasa kasar, menghina, bertengkar, mengejek dan marah-marah. Hasil wawancara menunjukkan gangguan berfikir atau intelegensi merupakan faktor penyebab agresi verbal pada siswa karena muncul pemikiran siswa yang tidak baik sehingga berbahasa kasar, menghina, bertengkar, mengejek dan marah-marah dapat menolong dirinya ketika diganggu.

\section{Gangguan Emosional}

Salah satu faktor yang sering memicu terjadinya agresivitas adalah faktor emosional yang ada pada individu. Ketika seseorang mengalami suatu kondisi yang kurang menyenangkan, maka emosi yang sering terlihat adalah emosi marah. Perasaan marah berlanjut pada keinginan untuk melampiaskannya dalam satu bentuk tertentu dan pada objek tertentu (Sarwono, 2009) Karena kurang matangnya emosi yang dimiliki oleh remaja maka mereka merespon permasalahan tersebut dengan agresivitas [13]. Emosi remaja dapat dikaitkan terutama dengan tekanan sosial dan tingkat kepercayaan diri yang mereka miliki untuk menghadapi kondisi baru. Emosi memainkan peranan penting dalam kehidupan individu karena membuat hidup bervariasi, menarik dan mendebarkan. Hidup tanpa emosi menjadi kusam, monoton dan bagaikan mesin. Jika emosi tidak diungkapkan dengan hati-hati, maka dapat menciptakan masalah dalam kehidupan seseorang, karena mereka mempengaruhi persepsi pikiran kita, sikap dan minat.

\section{Keluarga}

Perilaku agresif dapat diperoleh atau dipengaruhi oleh lingkungan.Lingkungan keluarga merupakan lingkungan terdekat bagi remaja, sehingga keluarga juga merupakan sumber bagi timbulnya agresi. Salah satu faktor yang diduga menjadi sebab timbulnya tingkah laku agresif adalah kecenderungan pola asuh 
tertentu dari orang tua (child rearing). Pola asuh orang tua juga merupakan salah satu faktor yang mempunyai peranan penting dalam pembentukan kepribadian anak, dimana keluarga adalah lingkungan yang pertama kali menerima kehadiran anak. Keadaan kehidupan keluarga bagi seorang anak dapat dirasakan melalui sikap dari orang yang sangat dekat dan berarti baginya. Dengan kata lain, pola asuh orang tua akan mempengaruhi perilaku anaknya[6]

\section{Teman Sebaya}

Teman sebaya adalah orang dengan tingkat usia dan kedewasaan yang hampir sama [14].Pengaruh teman sebaya dapat berdampak positif maupun negatif. Pengaruh teman sebaya yang positif akan membawa remaja belajar mengembangkan diri dan kreativitas bersama teman - temannya. Tapi teman sebaya juga dapat membawa pengaruh negatif. Apabila dia berada pada lingkungan yang negatif seperti narkoba, seks bebas, dan tawuran, maka kemungkinan besar akan terpengaruh juga.

Apabila remaja tidak mengikuti aturan atau perilaku teman sebayanya, maka remaja akan merasa diasingkan dari kelompoknya. Beberapa hasil dari penelitian juga menyebutkan bahwa remaja cenderung berperilaku agressif, seperti penelitian. Kuntari [15]yang menyebutkan bahwa semakin tinggi kematangan emosi remaja, maka akan semakin rendah agresivitasnya, begitu pula sebaliknya.

\section{Sekolah}

Menurut hasil penelitian [16] diketahui bahwa terdapat hubungan yang signifikan antara agresivitas siswa dengan iklim sekolah. Semakin baik iklim suatu sekolah akan semakin rendah tingkat kekerasan (agresivitas) yang terjadi di sekolah. Goldstein, S. E., Young, A., Boyd, [17] memperkuat temuan Barnes bahwa tingkat agresi relasional yang tinggi di sekolah berkorelasi dengan persepsi negatif siswa terhadap sekolah sebagai lingkungan yang tidak aman, dan memiliki atmosfer sosial yang kurang memuaskan. Selanjutnya Yıldız \& Sümer [18] menyatakan bahwa lingkungan sekolah yang tidak aman berhubungan erat dengan tingginya kekerasan yang dialami oleh siswa. Beberapa temuan penelitian tersebut menunjukkan hasil yang sama tentang adanya korelasi antara iklim sekolah yang negatif dengan agresivitas siswa di sekolah. Sebaliknya rasa aman di sekolah (iklim positif sekolah) menjadi faktor kuat yang mendukung keberhasilan proses belajar, perkembangan, dan pencapaian pretasi siswa [19]. Selain itu, siswa yang memiliki persepsi positif mengenai iklim sekolahnya akan lebih mungkin untuk bertindak dan menunjukkan sikap saling perduli terhadap sesama dan mencegah niat buruk dari sesama siswa [20] Iklim sekolah merupakan faktor penting yang tidak dapat diabaikan begitu saja. Dalam hal ini Freiberg [21]menyatakan bahwa keberadaan iklim sekolah dapat berpengaruh positif bagi terciptanya lingkungan belajar yang sehat, namun secara signifikan dapat pula menghalangi tercapainya proses pembelajaran. Haynes, Emmons dan Comer [22] mendefinisikan iklim sekolah sebagai kualitas dan konsistensi interaksi interpersonal di antara masyarakat sekolah yang dapat mempengaruhi perkembangan kognitif, sosial dan psikologis siswa. Menurut Loukas iklim sekolah adalah perasaan dan sikap yang ditimbulkan dari lingkungan sekolah. Iklim sekolah juga dapat didefinisikan sebagai persepsi terbuka dari individu mengenai lingkungan sekolah sebagai ruang belajar, ruang untuk berinteraksi dengan teman sebaya maupun dengan guru [20]

\section{Lingkungan}

lingkungan dimana kita tinggal senantiasa terbagi atas dua jenis, yaitu lingkungan fisik dan lingkungan non fisik. Lingkungan fisik meliputi segala hal yang ada di sekitar manusia yang sifatnya statis, pasif dan terlihat oleh mata (tangible). Sedangkan lingkungan non fisik adalah semua hal di luar diri manusia yang tidak terlihat secara kasat mata (intangible), namun senantiasa aktif dan dinamis, mengikuti pergerakan relasi sosial anggota di dalamnya. Lingkungan Non fisik di sekitar kita biasa disebut dengan lingkungan sosial. lingkungan secara fisik mempengaruhi perilaku para individu yang tinggal di dalamnya. Lingkungan yang tidak sehat dan kotor, penuh-sesak dan padat (slums) juga akan mempengaruhi keadaan fisik, sosial dan psikologis para penghuninya. Bahkan dikhawatirkan keadaan permukiman yang demikian ini berpotensi menjadi trigger terjadinya tindakan-tindakan anti sosial yang bisa menimbulkan tindakan- 
Putri Rahmaning Sekar

Psyche 165 Journal Vol 14 No 1 (2021) 27 - 31

tindakan maladaptive seperti halnya perilaku agresif para warganya. Bahkan, boleh jadi bisa menjadikan cikal bakal bagi terbentuknya perilaku maladaptive dan menyimpang bagi sebagian individu yang tinggal di dalamnya. Demikian halnya dengan lingkungan sosial, memiliki andil yang tidak kalah signifikansinya dalam pembentukan perilaku individu yang tinggal di dalamnya, termasuk pembentuk dan pencetus perilaku agresif.

\section{Kesimpulan}

Hasil studi literatur menunjukkan bahwa agresivitas tidak hanya dipengaruhi oleh faktor dari dalam diri individu saja (internal), tetapi juga dapat dipengaruhi oleh faktor dari luar (eksternal). Faktor internal tersebut meliputi: frustasi, gangguan berfikir dan intelegency remaja, serta gangguan perasaan/emosional pada remaja sedangkan faktor eksternal meliputi faktor keluarga atau teman sebaya, faktor sekolah dan faktor lingkungan.

\section{Daftar Pustaka}

[1] E. B. Hurlock, Psikologi Perkembangan - Suatu Pendekatan Sepanjang Rentang Kehidupan. 2010.

[2] D. Afandi, F. Chandra, D. Novitasari, I. R. Widjaja, and L. Kurniawan, "Tingkat penyalahgunaan obat dan faktor risiko di kalangan siswa sekolah menengah umum," Maj Kedokt Indon, 2009.

[3] A. H. Buss and M. Perry, "The Aggression Questionnaire," J. Pers. Soc. Psychol., 1992, doi: 10.1037/00223514.63.3.452.

[4] M. Guswani, Aprius and F. Kawuryan, "Perilaku Agresi pada Mahasiswa Ditinjau dari Kematangan Emosi," J. Psikol. Pitutur, 2011.

[5] S. W. Sarwono, Teori-Teori Psikologi Sosial. 2010.

[6] L. Berkowitz, Emosional Behavior: Mengenali perilaku dan tindakan kekerasan di lingkungan sekitar kita dan cara penanggulangannyaTitle. Jakarta: CV. Teruna Grafica., 2003.

[7] M. H. Kellner and B. H. Bry, "The effects of anger management groups in a day school for emotionally disturbed adolescents," Adolescence, 1999.

[8] M. Currie, "Doing Anger Differently: A group percussion therapy for angry adolescent boys," International Journal of Group Psychotherapy. 2004, doi: 10.1521/ijgp.54.3.275.40335.

[9] H. C. Lench, "Anger management: Diagnostic differences and treatment implications," Journal of Social and Clinical Psychology. 2004, doi: 10.1521/jscp.23.4.512.40304.

[10] E. Koeswara, Agresi Manusia. Bandung: PT Eresco, 1988.

[11] D. G. Myers, Psikologi Sosial Edisi 10. Jakarta: Salemba Humanika, 2012.

[12] S. W. \& E. A. M. Sarwono, Psikologi Sosial. Jakarta: Penerbit Salemba Humanikao, 2009.

[13] S. B. D. S. Gill, "Emotional Intelligence In Relation To Emotional Maturity And Emotional Competence Of Secondary School Students.," Glob. J. Multidiscip. Stud., vol. 4(6), pp. 200-204., 2015.

[14] Santrock, Life-Span Development: Perkembangan Masa Hidup. 2003.

[15] R. Kuntari, "Hubungan Antara Kematangan Emosi dengan Agresivitas Remaja.," J. Psikol. Univ. Muhammadiyah Surakarta, vol. 3, pp. 5-11, 2011.

[16] K. Barnes, S. Brynard, and C. de Wet, "The influence of school culture and school climate on violence in schools of the Eastern Cape Province," South African J. Educ., 2012, doi: 10.15700/saje.v32n1a495.

[17] C. Goldstein, S. E., Young, A., Boyd, "Relational Aggression at School: Associations with School Safety and Social Climate," J. Youth Adolesc. USA., vol. Vol. 37., p. Hal 641-654, 2008.

[18] E. Ç. Yıldız and Z. H. Sümer, "Saldırgan Davranışlarını Yordamada Çevresel Risk, Çevresel Güvenlik ve Okul İklimi Algısı. (Turkish)," Perceived Neighborhood Risk, Neighborhood Saf. Sch. Clim. Predict.

Aggress. Behav., 2010.

[19] B. Johnson and J. J. Stevens, "Student achievement and elementary teachers' perceptions of school climate," Learn. Environ. Res., 2006, doi: 10.1007/s10984-006-9007-7.

[20] M. D. Syvertsen, A. K., Flanagan, C. A,. \& Stout, "Code of silence: students perception of school climate and willingness to intervene in a peers dangerous plan," J. Educ. Psychol., vol. 101(1), pp. 219-232., 2009.

[21] H. J. Freiberg, School climate: Measuring, improving and sustaining healthy learning environments. 2005.

[22] E. Hoffman, L. L., Hutchinson, C. J., \& Reiss, "On improving school climate: Reducing reliance on reward and punishment," Int. J. Whole Sch., vol. 5(3), 2009. 